Article

\title{
Additive Manufacturing Redesigning of Metallic Parts for High Precision Machines
}

\author{
Manuela Galati *(D), Flaviana Calignano $\mathbb{D}$, Marco Viccica and Luca Iuliano \\ Department of Management and Production Engineering (DIGEP)-Integrated Additive Manufacturing \\ Center (IAM)-Politecnico di Torino, Corso Duca Degli Abruzzi, 24-10129 Torino, Italy; \\ flaviana.calignano@polito.it (F.C.); marco.viccica@polito.it (M.V.); luca.iuliano@polito.it (L.I.) \\ * Correspondence: manuela.galati@polito.it; Tel.: +39-011-090-4569
}

Received: 3 February 2020; Accepted: 26 February 2020; Published: 1 March 2020

\begin{abstract}
The conventional approach to design and manufacturing often has geometries with an efficient material distribution. For the high-precision machines, that approach involves the design of heavy components that guarantees the stiffness requirements. However, the higher the weight of the part, the higher inertia it has. As a result, when the feed axes are accelerated, the inertial forces deform the machine components and the precision of the machine is reduced. This study investigated the designing for additive manufacturing (DfAM) and designing for assembly (DfA) to increase the material efficiency of components for high-precision applications. A new methodology which considered the design and manufacturing issues and machining as well is given. A comprehensive model for cost evaluation of the part is presented. The case study refers to the rails and the bracket that support and move the flying probe of a testing machine for micro-electromechanical systems (MEMS). The weight of the rails has been decreased by $32 \%$ and the components to be assembled have been reduced from 16 to 7 . The optimized bracket is more than $50 \%$ stiffer than the original one, $10 \%$ lighter, and economically competitive.
\end{abstract}

Keywords: design for additive manufacturing (DfAM); displacements; laser powder bed fusion (L-PBF); manufacturing constraints; stiffness; costs

\section{Introduction}

In recent years, the development of additive manufacturing (AM) technologies has led to numerous opportunities to fill the gap between optimal design and product application. The advantages of AM over conventional subtractive or formative methods clearly emerge when considering the great design freedom that can be achieved [1-3]. AM technologies allow fully dense and near-net-shaped parts to be produced with complex structures made of excellent materials. Industrial applications can be found for metal components [4], for which traditional manufacturing processes are expensive or difficult to apply [5]. The geometries that result from such design techniques as topology optimization (TO) [6-10] are examples of such geometries [1]. The so-called design for AM (DfAM) is being explored to show the design opportunities that are enabled by the adoption of both TO and AM [11,12]. At the current state-of-the art, components for structural applications are redesigned to achieve both weight reduction and performance improvement. In these components, TO has been conducted so far by introducing a decrease in stiffness [13] or using more performing materials specifically developed for AM technologies [14-16]. Such solutions may be effective in several fields, but they may not be practicable when the choice of new material involves a large increase in the cost of a component, or a much lower component stiffness. The stiffness of the structural components (such as the measuring probe, brackets, and the rails that support the measuring probes and motors) plays a key role in the accuracy of the machine, especially for high precision applications [17]. The use of conventional design methods 
and manufacturing systems lead to heavy and large components as final output [18] to guarantee high rigidity and limited deformations and vibrations $[19,20]$. However, the increased component weight (inertial forces) involves higher bending forces which may cause larger measurement errors [17]. Additionally, the accumulation of mass forces implies the use of lower traverse speeds that decrease machine productivity [21]. The aim of this research has been to show how such critical issues can be overcome by exploiting the benefit of DfAM. The study focused on the redesigning of some component of a high precision machine that uses flying probes to test the boards of micro-electromechanical systems (MEMS). Considering that only small production lots are produced per year and each testing machine is highly customized according to the specific requirements of each customer, the redesign lends itself well to production through metal AM systems. Because of the requirements of high dimensional accuracy, the laser powder bed fusion (L-PBF) technique is considered [22]. A comprehensive approach was proposed in which material distribution optimization, design for L-PBF, and design for assembly (DfA) are considered. This approach aimed also to overcome the current limitation of the design techniques and building volume of the L-PBF systems. The feasibility of the components and the machining operations have been investigated, and a comprehensive and detailed cost model has been developed and applied.

\section{Design for L-PBF}

During an L-PBF process, a laser source fuses a region of a metallic powder bed according to the computer aided design (CAD). When the one layer has been completed, the building platform is lowered, and the next layer of powder is deposited on the previous one. The process is then repeated until the part is completely built. Production by L-PBF (black flow line in Figure 1) involves several steps: the cleaning of loose powder from the part and post-process operations, including stress-relieving, removal of the supports, shot peening, heat treatments, and finishing operations [23].

The design of a part and its orientation on the building platform together with the choice of process parameters play a key role in the success of the process. From this point of view and according to one of the main rules for correctly using AM technologies, the design for L-PBF should focus on using the material only where necessary. Designing for L-PBF means considering during the design phases not only the constraints of the process, such as the minimum dimension of the feature, but also all activities that aim to guarantee the process and the part compliances, including the next manufacturing steps (support removal and machining). Here, the dimensional and the surface qualities and the metallurgic properties to be achieved on the part need to be considered [24].

For the part design, the DfAM and the DfA are the only possible design methodologies related to AM [25]. However, a comprehensive approach considers five steps: (1) the acquisition of the CAD model; (2) the part optimization; (3) the resulting new design; (4) the optimization of the orientation (purple square), and (5) the design verification. The optimized part from a structural point of view is the input for the subsequent steps. Advanced design techniques, such as TO, can be applied in this phase [2]. The optimized geometry needs to be checked under the geometrical limitation of the process. Adam et al. [26] provided a classification of these limitations, but it should be noted that design rules for L-PBF must not be considered as constraints but as modifiers during the design optimization [27]. Points 3 and 4 are iterative steps which consider reducing as little as possible the modifications of the optimize geometry resulting from step 2 . Point 4 , together with the support optimization, considers all of the above-mentioned activities. The evaluation of the optimal orientation is a hot topic in literature and usually is mainly based on the avoiding of support structures [28]. Leary et al. [29] proposed a methodology to evaluate the optimal build orientation according to the manufacturing time and component mass. However, because the L-PBF components are only near-net-shape, finishing operations should be carefully considered. Additionally, since support structures cannot be completely avoided, proper support design should be considered as leverage for the process [30]. 
The optimization phases (orientation and supports) are developed here with the aim to limit the support structure and the allowance for the machining operations. The iterative flow (red flow line in Figure 1) is maintained between the product design and the optimizations steps that may be involved in partial design modifications.

The part orientation phase (purple square in Figure 1) has the purpose of optimizing the part orientation, position, and arrangement on the build platform because they can have an impact on the stability and speed of the process as well as on the properties of the components e.g., on residual stress-induced warping, known as curl effect. When the recoating blade deposits a new layer of powder on the previous one, it approaches the already fused area. If the molten section is large, the force applied by the blade on the part could detach it from the building platform or lead to the stalling of the blade motor. To reduce the contact length, the part should be rotated by a small angle (from 5 to 8 degrees on the building platform with respect to the blade).

Cylindrical surfaces are the first features that need to be considered. The best solution, which reduces the dimensional error, is the positioning of the cylindrical surfaces with their axis perpendicular to the building platform. Among the surfaces, the accuracy of the internal ones has the priority due to the difficulty to machine these kinds of surfaces. Anyway, the accessibility of the area to remove the support should always be verified. In fact, the purpose of adjusting the orientation of a part is also to alter the inclined angles of the overhanging surface to minimize the number of support structures. Support structures locally reduce the dimensional and the surface quality, and therefore they limit the design freedom due to the additional post-processing operations required to remove the supports. Similarly, support structure should be avoided on thin features that could be damaged during the support removal operations. The orientation should also minimize the number of surfaces to be finished. If the rough surface or support structure cannot be avoided, those surfaces should be the same that, according to the design requirements, need to be machined. Therefore, e.g., the best solution is to move and rotate the part until the surfaces to be machined are the same that serve to attach the support to the part. Overall, it should be considered:

- Adding a suitable allowance, albeit only to the features that need to be finished or where the prescribed roughness is lower than the surface roughness obtained when using the L-PBF process. Post heat treatments that can cause modifications of the final geometry should also be considered;

- From the design point of view, since the surface roughness depends on the orientation of the part in the build volume, the part should be oriented to minimize the finishing operations;

- If the holes need to be finished by machining, consider directly machining the holes;

- Because complex geometries can lead to problems related to the positioning of the part during the finishing operations, flat surfaces should be designed as reference surfaces for the subsequent operations. Specific tools may be produced directly, by means AM processes for metals or polymers, and used to fasten the component to a standard tool;

- Some features could be designed with the aim to support the part during the L-PBF process and as an aid for the fastening of the component during machining. On the other hand, the features to be machined should be simplified according to the design for conventional manufacturing rules.

The next step "support design" (blue square in Figure 1) aims to design proper support structures that allow fixing the part to the building platform, to support critical surface angles and to prevent deformation of the part due to heat accumulation and thermal stresses [30]. Additionally, the support design workflow helps in designing suitable support structures that are easy to remove and minimize the machining. 




Figure 1. Design and manufacturing for an laser powder bed fusion (L-PBF ) process. 


\section{Economic Analysis}

The overall objective of the economic analysis is to estimate the manufacturing costs. Differently to the literature on the conventional manufacturing processes, the costs for metal AM processes have only been dealt with in a limited number of case studies, and a well-structured approach has not yet been presented. Rickenbacher et al. [31] introduced a cost model for L-PBF that considered only some components to calculate the manufacturing costs. However, they neglected some relevant items, such as the fixed cost of the machine due to the maintenance and the heat treatment required to release the thermal stresses. Moreover, they introduced arbitrary factors to model the frequency of material changes, which was evaluated on the basis of a single build rather than a single part. Baumers et al. [32] proposed a general production cost model for electron beam melting (EBM) and direct metal laser sintering (DMLS), which is the EOS GmbH tradename for their L-PBF process machine. Their study estimated the costs according to machine usage. However, they did not consider any design optimizations and neglected the partition of the machine cost of when different components are produced in the same job. A general estimation model of the manufacturing costs of AM processes

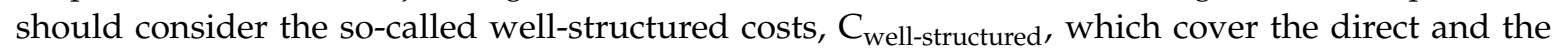
indirect costs and can be computed for a single produced part. The direct costs refer to the costs that are directly associated with the production. They are absent if the production is halted. The indirect costs refer to those costs which cannot be avoided when the production is interrupted, such as the salaries of the administrative staff. The direct costs and the indirect costs are functions of the build time of each part.

As far as the indirect costs are concerned, the following costs were calculated:

- Machinery depreciation, which is distributed over the total working hours of the year and computed in proportion to the build time, according to Equation (1):

$$
\mathrm{S}=\frac{\mathrm{C}_{\text {machine }}(1+\mathrm{i})^{\mathrm{n}}}{\mathrm{n}} \cdot \frac{\mathrm{t}_{\text {build }}}{\mathrm{h}_{\text {year }}}
$$

where $C_{\text {machine }}$ is the cost of the machine, $\mathrm{n}$ is the number of years, which is usually assumed equal to $5, \mathrm{i}$ is the interest, $\mathrm{h}_{\text {year }}$ is the annual working hours, and $\mathrm{t}_{\text {build }}$ is the building time.

- Administrative costs, which are distributed over the total working hours per year and computed considering the build time;

- The costs due to the renting the premises are computed considering the space occupied by the machine and the auxiliary systems.

The direct costs are:

- The design costs per part $C_{d}$, which can be referred to as the time required to design and optimize the geometry. Since an optimized geometry must be obtained from a manufacturing design, $C_{d}$ also refers to the time spent assembling the job (all activities included in checking Figure 1 such as the creation of the STL file, orientation, creation of the support structures, slicing and setting the process parameters). Thus, $\mathrm{C}_{\mathrm{d}}$ can be computed as:

$$
\mathrm{C}_{\mathrm{d}}=\frac{1}{\mathrm{~N}_{\mathrm{ps}}}\left[\left(\mathrm{C}_{\text {doper }}+\frac{\mathrm{C}_{\mathrm{CADsw}}}{\mathrm{h}_{\mathrm{CADsw}}}\right) \mathrm{t}_{\mathrm{d}}+\left(\mathrm{C}_{\text {doper }}+\frac{\mathrm{C}_{\mathrm{CAMsw}}}{\mathrm{h}_{\mathrm{CAMsw}}}\right) \mathrm{k}_{1} \mathrm{t}_{\mathrm{job}}\right]
$$

where $C_{\text {doper }}$ is the designer's hourly rate, expressed in $€ / h, C_{C A D s w}$ and $C_{C A M s w}$ are the cost per user of the annual software license for the CAD model and the job preparation, respectively, $\mathrm{h}_{\text {CADsw }}$ and $\mathrm{h}_{\text {CAMsw }}$ are the number of hours of use of the software per year ( $€$ /year) for the CAD model and the job preparation, respectively, $t_{d}$ is the time that is required for the design and $t_{j o b}$ is the time that is required to prepare the job, and it is weighed by $k_{1}$, which is the ratio between the volume of the part (including the support structures and the allowances) $\mathrm{V}_{\mathrm{O}+\mathrm{A}+\mathrm{S}}$ and the total job volume $\mathrm{V}_{\mathrm{job}} . \mathrm{k}_{1}$ is used to account the building of parts with different geometries in the same job. 
$\mathrm{k}_{1}$ considers that the larger the volume of the part, the more time is required for the building time. $\mathrm{N}_{\mathrm{ps}}$ is the total number of parts that have to be produced.

- Setup Cost per part, which refers to the preparation of the machine before the job starts. It includes the cost of filling the dispenser, $\mathrm{C}_{\text {fill }}$, the cost of preparing and checking the chamber, $\mathrm{C}_{\text {env }}$ (e.g., argon flow), the cost of resurfacing the build platform, and $\mathrm{C}_{\text {build plat, }}$ the cost of removing the supports after the part has been removed. Build platforms are usually re-surfaced by milling operation [33]:

$$
\mathrm{C}_{\text {setup }}=\mathrm{k}_{2} \mathrm{C}_{\text {fill }}+\mathrm{k}_{1} \mathrm{C}_{\text {env }}+\mathrm{k}_{3} \mathrm{C}_{\text {build plat }}
$$

where $C_{\text {fill }}=C_{\text {oper }} \cdot t_{\text {fill }}$, and $t_{\text {fill }}$ is the time required to fill the dispensers. $\mathrm{C}_{\text {build plat }}=\left(\mathrm{C}_{\text {machining }} \cdot \mathrm{W}(\mathrm{H}+\mathrm{ex})\right) /\left(0.50 \mathrm{Dv}_{\mathrm{o}}\right)$ is the cost of resurfacing the build platform by machining in a single operation. $\mathrm{C}_{\text {machining }}$ is the hourly cost of the milling machine, $\mathrm{W}$ and $\mathrm{H}$ are the dimensions of the build platform, ex is the sum of the approach length and the overtravel, $\mathrm{D}$ is the diameter of the mill, and $\mathrm{v}_{\mathrm{o}}$ is the material removal rate $(\mathrm{mm} / \mathrm{min})$. As $\mathrm{k}_{1}, \mathrm{k}_{2}$, and $\mathrm{k}_{3}$ take into account the building of parts with different geometries in the same job, $\mathrm{k}_{2}$ considers the percentage of material utilized for the building of the part against the quantity used to fill the dispensers (Mat filldisp $_{\text {). Mat }}$ filldisp considers a quantity of powder expressed in $\mathrm{kg}$ that corresponds to the quantity of material to fill a building volume corresponding to the maximum height of job multiplied for the dose factor. The dose factor depends on the saturation of the build platform. An additional $20 \%$ of material could be also considered. $\mathrm{k}_{3}$ considers that the larger the projected area of the part on the build platform is, the higher the cost of the part for the milling operations:

$$
\begin{gathered}
\mathrm{k}_{2}=\frac{\mathrm{W}_{\mathrm{m}}}{\text { Mat }_{\text {filldisp }}} \\
\mathrm{k}_{3}=\frac{\text { surface of the build platform occupied by the part }}{\text { total surface of the occupied build platform }}
\end{gathered}
$$

where $\mathrm{W}_{\mathrm{m}}$ is the quantity of material used to build the part and Mat filldispis $_{\text {in }}$ the quantity of material used to fill the dispenser.

When Argon is used, $\mathrm{C}_{\text {env }}$ can be computed as follows:

$$
\mathrm{C}_{\mathrm{env}}=\mathrm{C}_{\mathrm{Ar}} \mathrm{V}_{\mathrm{Ar}}+\mathrm{C}_{\mathrm{oper}} \mathrm{t}_{\mathrm{oper} A r}
$$

where $C_{A r}$ is the price of the Argon per $\mathrm{m}^{3}$, and $V_{A r}$ is the total volume of Argon used to fill the build chamber and achieve the right pressure before the process starts. $t_{\mathrm{operAr}}$ is the time required for the operator to start and control the procedure.

- Production cost, $\mathrm{C}_{\text {production, }}$ refers to the direct cost of building the part. This cost includes the energy consumption of the machine and of the other systems, including gas consumption. In addition, this cost includes the maintenance of the machine and the other systems during which a downtime period is required. These costs are computed as indirect costs and are a function of the time that the machine is used to build the part. However, these costs are not taken into account when the machine is not utilized, unlike the indirect costs, which still have to be considered, even when the production is halted:

$$
\mathrm{C}_{\text {production }}=\mathrm{C}_{\text {gas }}\left(\mathrm{t}_{\text {exp }}+\mathrm{k}_{4} \mathrm{t}_{\text {cooling }}\right)+\mathrm{C}_{\mathrm{AM}} \mathrm{t}_{\text {build }}
$$

where $\mathrm{C}_{\mathrm{gas}}$ is the hourly rate cost of the gas that is used during the building and cooling of the part, $\mathrm{C}_{\mathrm{AM}}$ is the direct hourly rate cost of the AM system and is the sum of the costs of the energy consumption per hour, of the maintenance of the machine and the other $C_{m m}$ systems. 
$\mathrm{C}_{\mathrm{mm}}$, which is distributed over the total hours between two subsequent maintenance operations of the $t_{b 2 m}$ systems, is calculated as follows:

$$
C_{\mathrm{mm}}=\sum \frac{\left(\mathrm{C}_{\mathrm{oper}} \mathrm{t}_{\mathrm{mm}}+\mathrm{C}_{\mathrm{rc}}\right)}{\mathrm{t}_{\mathrm{b} 2 \mathrm{~m}}}
$$

where $C_{\text {oper }}$ is the operator's hourly rate cost, expressed in $€ / h, t_{\mathrm{mm}}$ is the time that is required for the maintenance operations and $\mathrm{C}_{\mathrm{rc}}$ is the cost of the replaced components.

- Material cost, $\mathrm{C}_{\mathrm{mat}}$, is obtained from the total material quantity $\mathrm{W}_{\mathrm{m}}$ and is calculated according to Equation (9). The cost of powder, $C_{\text {powder }}$, refers to the cost per kilogram of powder:

$$
\mathrm{C}_{\text {mat }}=\mathrm{W}_{\mathrm{m}} \mathrm{C}_{\text {powder }}
$$

- The manufacturing cost is related to the build time, and it includes the idle time and the exposure time, $t_{\text {exp }}$, per part, as presented in Equation (10):

$$
\mathrm{t}_{\text {build }}=\mathrm{k}_{1}\left(\mathrm{t}_{\text {heating plat }}+\mathrm{t}_{\text {aux }}+\mathrm{t}_{\text {fillAr }}\right)+\mathrm{t}_{\text {exp }}+\mathrm{k}_{4} \mathrm{t}_{\text {cooling }}
$$

where $t_{\text {heating plat }}$ is the time required to heat the build platform, $t_{\text {aux }}$ is the extra time required before starting the process (the cleaning and levelling processes of the build platform, compacting and leveling the powder, cleaning the lens and lens cover), $t_{\text {fill }} \mathrm{Ar}$ is the time required to fill the build chamber with argon, and $t_{\text {cooling }}$ is the time required to cool the part. $k_{4}$ is a coefficient that is introduced to consider the building of parts with different geometries in the same job and is defined as follows:

$$
\mathrm{k}_{4}=\left(1-\frac{\text { the total surface of the part }}{\sum \text { the surface of the parts }}\right)
$$

$\mathrm{k}_{4}$ considers that the larger the surface of the part is, the more rapid the cooling.

- The post-processing cost, $\mathrm{C}_{\text {post proc, }}$ only includes the operations that are mandatory to consider the $\mathrm{AM}$ process complete. For these reasons, $\mathrm{C}_{\text {post proc }}$ contains the cost of removing the support structures, $C_{\text {rem supp }}$, the cost of the post treatment, $C_{\text {post treat }}$, the cost of the heat treatment to release the residual stresses for the L-PBF process, and the cost of polishing the part, $\mathrm{C}_{\text {polishing, }}$ by shot peening:

$$
\begin{aligned}
& \mathrm{C}_{\text {post proc }}=\mathrm{k}_{3} \mathrm{C}_{\text {rem supp }}+\mathrm{k}_{1} \mathrm{C}_{\text {post treat }}+\mathrm{C}_{\text {polishing }} \\
& \mathrm{C}_{\text {rem supp }}=\left(\mathrm{C}_{\mathrm{EDMV}} \mathrm{v}_{\mathrm{oEDM}}+\mathrm{C}_{\mathrm{saw}} \mathrm{V}_{\mathrm{oGr}}\right) \mathrm{l}_{\text {build platform }}+\mathrm{C}_{\text {oper }} \mathrm{t}_{\text {rem }}
\end{aligned}
$$

The support can be removed by means of a wire electro discharge machining (EDM) process, manually or by sawing. $\mathrm{C}_{\mathrm{EDM}}$ and $\mathrm{C}_{\mathrm{saw}}$ are the hourly costs of the EDM machine and of the saw, respectively. $\mathrm{v}_{\mathrm{OEDM}}$ and $\mathrm{v}_{\mathrm{oGr}}$ are the material removal rates for EDM and sawing processes, respectively. $l_{\text {build platform }}$ is a length of the build platform and $t_{\text {rem }}$ is the time required to remove the support structures manually. $C_{\text {post treat }}$ and $C_{\text {polishing }}$ are evaluated as the hourly costs for the machine and the time needed to complete the operation. $\mathrm{k}_{3}$ considers that more supports are necessary for larger surfaces. $\mathrm{k}_{1}$ considers that the larger the parts are, the longer the time needed in the oven.

- Finishing costs, which refer to the additional operations necessary to finish the part and achieve the required dimensional, geometrical, and surface accuracy. This information should be defined at the design stage.

\section{Case Study}

The study has dealt with the system (Figure 2) that supports and moves a flying measure probe in a working volume. Each test machine has eight flying measurement probes: four to acquire signals 
from the top of the board and four to acquire signals from the bottom of the board. The high precision flying probe is supported by a bracket which also contains the vision system and the lighting system that are used to acquire images during the measurements, the mechanisms that are used to move the flying measure probe and the data collection systems. The flying probe and the system used to collect data and to move the probe are joined to the bracket by means of six screws, while the vision system and its data collection system are joined to the bracket with four bolts. The whole system (bracket, flying probe and vision system) is joined to the X-rail by four bolts and aligned precisely with two dowel pins. The linear motor guide is assembled in the upper part of the X-rail. The X-rail also contains the motor stator magnets which are enclosed in the rail by two side covers. The $X$-rail is joined to the bottom part of the Y-rail and is equipped with another linear motor. The electric motors move the whole system linearly along the $X$ and $Y$ axes. The probe can also be moved along the $Z^{*}$ axis, which is rotated by a certain angle with respect to the normal of the XY-plane. The overall dimensions of the two rails (orange in Figure 1) are $220 \times 690 \times 101 \mathrm{~mm}^{3}$ and the total weight is around $5000 \mathrm{~g}$. The maximum envelope for the bracket is $150 \times 60 \times 60 \mathrm{~mm}^{3}$. The bracket weighs $203 \mathrm{~g}$, while the whole system (probe, vision and lighting systems) weighs about $1400 \mathrm{~g}$.
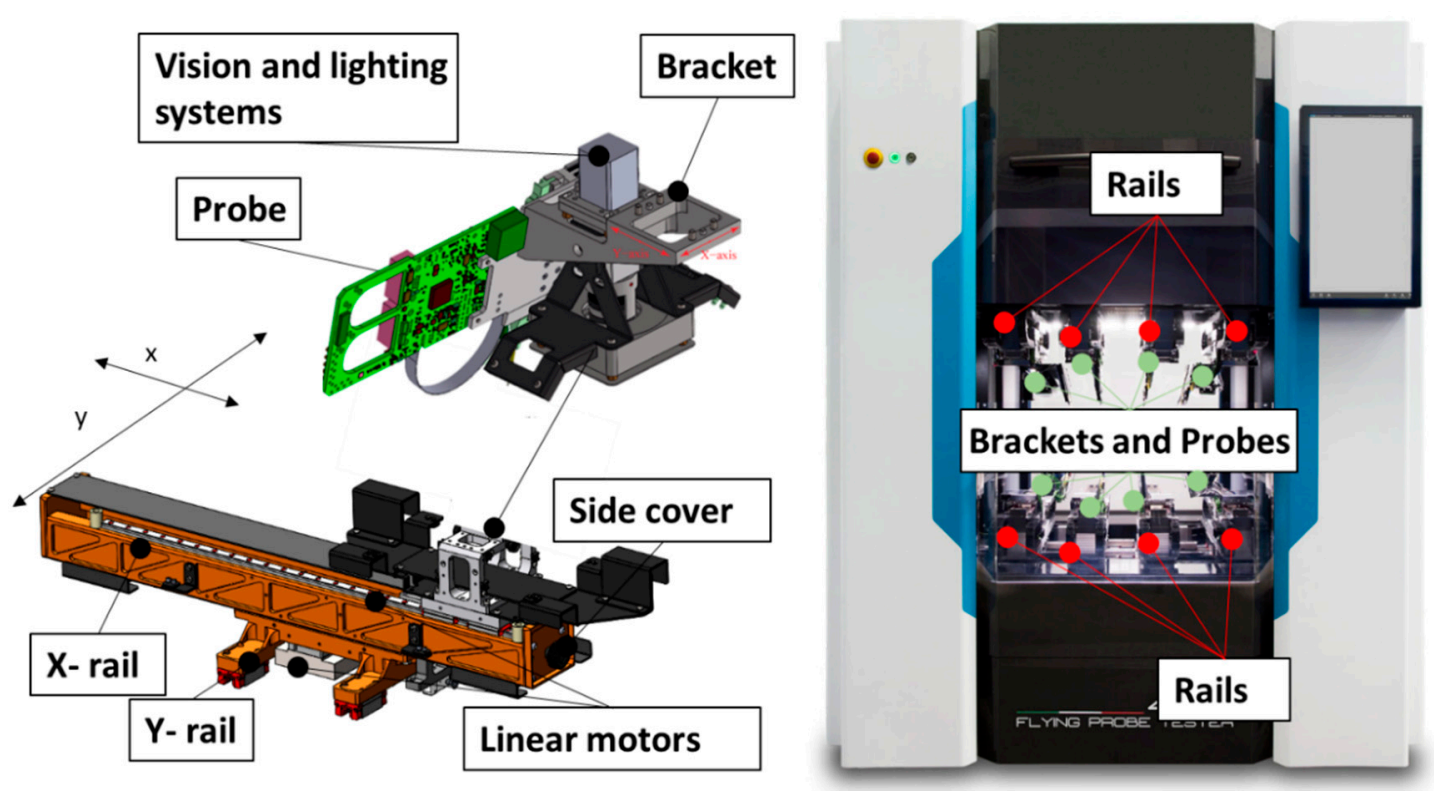

Figure 2. Case study. The systems that are subjected to redesigning are the $\mathrm{X}$ and $\mathrm{Y}$ rails and the bracket.

From the structural point of view, the most critical components for the accuracy of the machine and its dynamics are the two rails and the bracket. Because of the low number of parts produced per year (around 400 parts), a three-axis milling machine is used today to shape the components from raw aluminum 7075 alloy ingots.

The part of the system that considers the two rails includes 16 elements and requires 12 operations to join the two rails. The weight of these elements lies on the linear motor and affects the acceleration and deceleration ramps when the flying probe is moving in the working volume. Owing to the design criterion which lies to the high stiffness, the system is subjected to low stresses. The redesigning of the rails is aimed at streamlining the assembly in order to reduce the geometric errors that are accumulated and propagated, step by step, during the assembly process and which may affect the machine accuracy [34]. Redesigning is also aimed at reducing the total weight while maintaining stiffness. The design limitations, due to the larger rail dimensions $(690 \mathrm{~mm})$ than for most industrial metal component AM systems, need to also be considered at the design stage together with subsequent machining operations. 
The current design of the bracket exhibits a maximum displacement of over $30 \mu \mathrm{m}$, which exceeds the design requirements of $20 \mu \mathrm{m}$. The generated bending excess affects the position of the probe and the precision of the measurements. This error is currently compensated for by adopting suitable algorithms to adjust the probe positioning. From an industrial point of view, this choice is the best compromise between the time and costs necessary to design and manufacture (machine and component set, tools, etc.) the bracket. The bracket redesign is aimed at increasing the stiffness to that of the requirement $(20 \mu \mathrm{m})$ while maintaining its original weight to avoid an increased load on the electric motors.

Both components are designed to be produced using gas atomized AlSi10Mg powder, as it has similar properties to the original material. The material properties are reported in Table 1. Exact details about the machine, the geometries, the load conditions and the working cycle considered in this case study cannot be disclosed for confidentiality reasons. However, this should not rule out the understanding of the main findings of the case study.

Table 1. Material properties: comparison of Aluminum 7075-T6 for the three-axis milling machine and AlSi10Mg for L-PBF systems.

\begin{tabular}{ccc}
\hline Property & Aluminum 7075-T6 & A1Si10Mg \\
\hline Density [kg/m $\left.{ }^{3}\right]$ & 2810 & 2670 \\
Young's Modulus [MPa] & 71,700 & 75,000 \\
Yield Strength [MPa] & 503 & 350 \\
\hline
\end{tabular}

\subsection{Design of the Rails}

A simplified model of the original system was initially implemented in Inspire $^{\mathrm{TM}} 2018$ SolidThinking ${ }^{\circledR}$, version 2018, build 9508, to analyze its mechanical behavior. The probe, and the vision and the lighting systems were modelled as concentrated masses. The magnetic forces from the linear motor were simulated as vertical loads. A finite element (FE) method was used to solve the model. As expected, the system showed an almost uniform stress distribution and high equivalent stress of around $20 \mathrm{MPa}$, which is far below the limit of the material (Table 1). As already mentioned, the low stresses are due to the high stiffness design criterion. Thanks to the low stress (see supplementary file), the part can be redesigned freely considering only the peculiarity of the L-PBF process. The components of the system were therefore redesigned to achieve an efficient new material distribution and weight reduction while only coupling areas were constrained.

As far as the $\mathrm{X}$-rail is concerned, the design starts with a redesigning of the vertical walls (Figure 3a,b). Each vertical wall was replaced by two thin honeycomb-structure walls. These structures were demonstrated to be self-supported, and allow better stress distribution and light. The walls were also placed out of sync in order to distribute the stresses more evenly during the production of the components and during operation. A new material distribution was considered for the bottom wall using the Voronoi algorithm (Figure 3c). The cover was then welded to the rail (Figure 3d) to improve the stiffness of the rail and it was shaped like a cross. A similar approach was followed to redesign the Y-Rail (Figure 3e).

After the redesign of every single part, the parts were assembled and unnecessary features were removed. The whole system was therefore redesigned to be produced as a single monolithic part as follows. The two rails were then welded together. However, the component had to be split into three parts to fit most commercial and industrial L-PBF systems. Owing to the dimensions of the new parts, with the aim to produced them in a single job, an EOS M400 machine $\left(400 \times 400 \times 400 \mathrm{~mm}^{3}\right)$ has been considered for the production. Figure 4 a shows the results of the optimization phase (Section 2 and Figure 1) in which the support structures and the surface finishing are minimized. In this way, only the top surfaces of the $X$-rail, and the bottom surfaces of the $X$ and $Y$ rails have to be finished. The bottom surfaces are finished directly by EDM when the parts are removed from the building platform. The top surfaces of the X-rail are machined by milling after the assembly of the parts to 
ensure a good geometrical tolerance so that they can be joined to the linear motor guides. Figure 4 shows a simulation of the fastening systems during a milling step.

Original Design

(a)

(b)

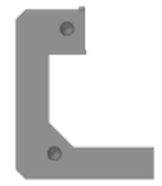

(c)

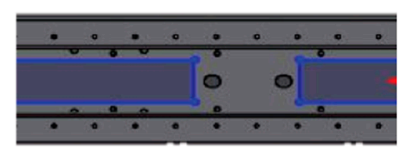

(d)

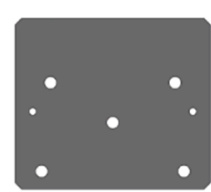

(e)

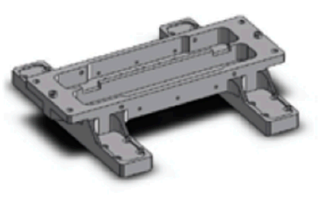

New Design
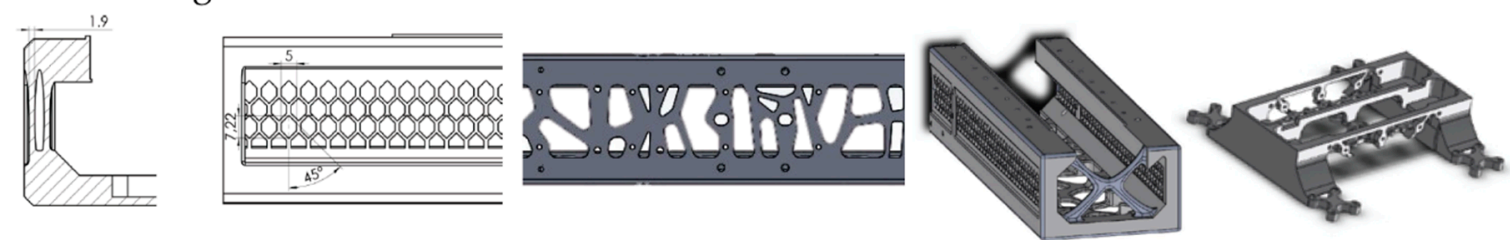

Figure 3. Details of the redesigned features for (a-d) the X-rail and (e) the Y-rail.

(a)

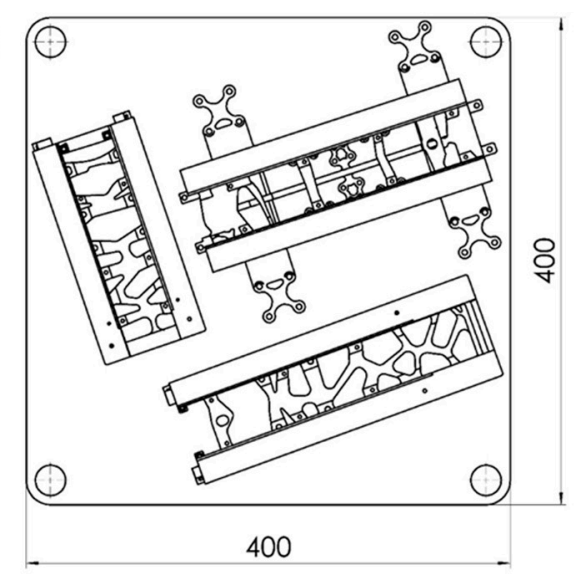

(b)

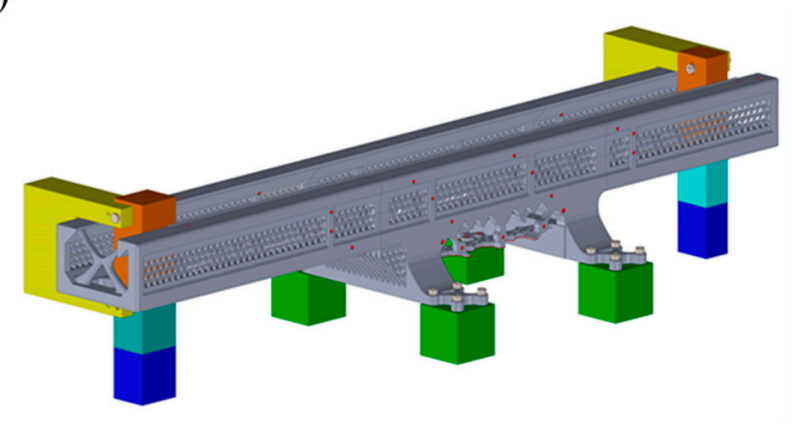

Figure 4. (a) manufacturing orientation for L-PBF production by EOS M400 and (b) machining using a three-axis machine.

According to the support optimization indications (Section 2 and Figure 1), all surfaces were modified to avoid the need of support structures (e.g., Figure 5a) and where the geometrical features were not accessible for manual or mechanical support removal (e.g., Figure $5 c$, an internal section of the y-rail). A grid (Figure 5d) that also works as a support during the L-PBF process was designed to increase the stiffness of the systems. A shaft-hub interference fit was designed (Figure 5e) to assemble the three parts (details provided in the supplementary file). The connection only included features that are self-supported. The connection between the two parts was also ensured by two bolts (Figure 5b). The component parts were all numbered to make the assembly easier (e.g., Figure 5a red square). After the geometry modification, Figure 6 shows the result of the support optimization according to Section 2 and Figure 1. 
(a)

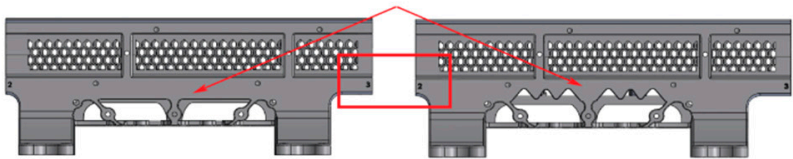

(c)

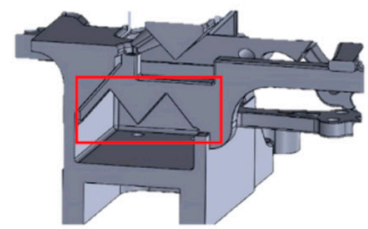

(d) (b)
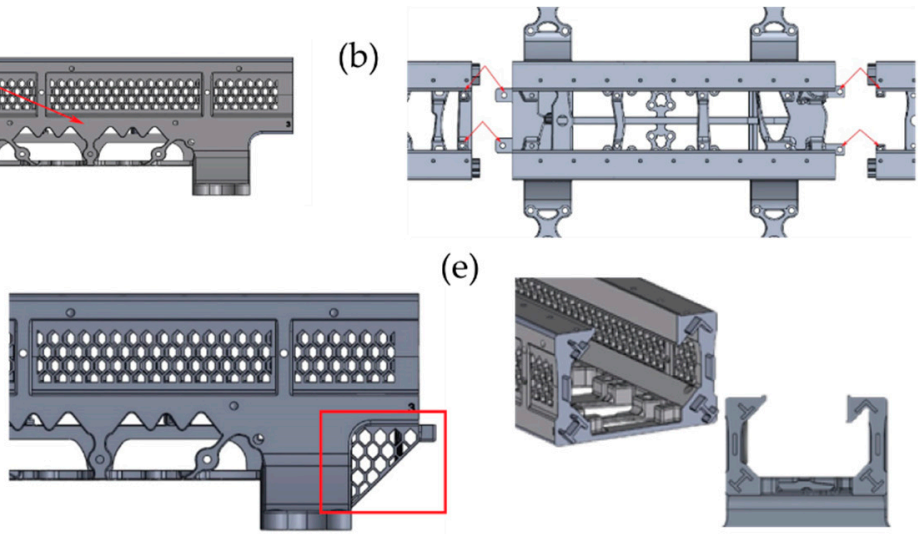

(e)

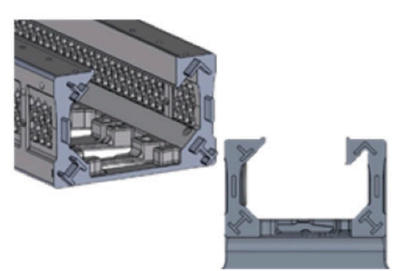

Figure 5. Modifications of the part features according to the support optimization procedure presented in Section 2. (a) modification of the bottom part of the rail to reduce the number of support structures; (b) removing material and modification of the surfaces to avoid inaccessible area for the support removal (a section is showed in (c)) and adding a link to improve the assembly strength; (d) features that support the overhang both during the construction of the part and the working conditions; (e) particulars of the shaft-hub interference fit (details are provided in the supplementary file).
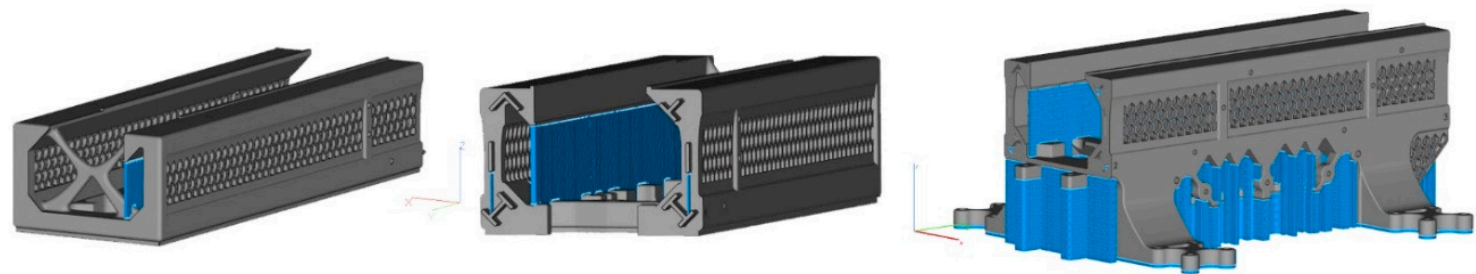

Figure 6. The layout of the parts with the support structure (in blue). All supports can be removed manually, except the ones on the bottom surfaces which are removed during the detachment of the parts from the building platform by EDM.

Figure 7 shows the differences between the original and the new design. The displacements showed the same distribution. The new material distribution that led a reduction in weight of about $32 \%$ was achieved as a result of the implementation of the new design, without any significant changes in terms of stiffness. A technical prototype for the experimental tests was produced according to the designed working cycle. The total production time, including the heat treatment, the support removal, the EDM, and the finishing operations, was about three days. The final component is shown in Figure 8. The total material swarf was about $200 \mathrm{~g}$. The material cost (powder cost equal to $65 € / \mathrm{kg}$ ) of producing the component was around $€ 197$, which is comparable with the material cost of the original component (€196 [35]). However, considering that the initial components were machined from an ingot [35], the material saving, with respect to the original component, was around $99 \%$. The assembly operation flow was simplified because all the operations to join the rails and the covers were removed. 
Original Design
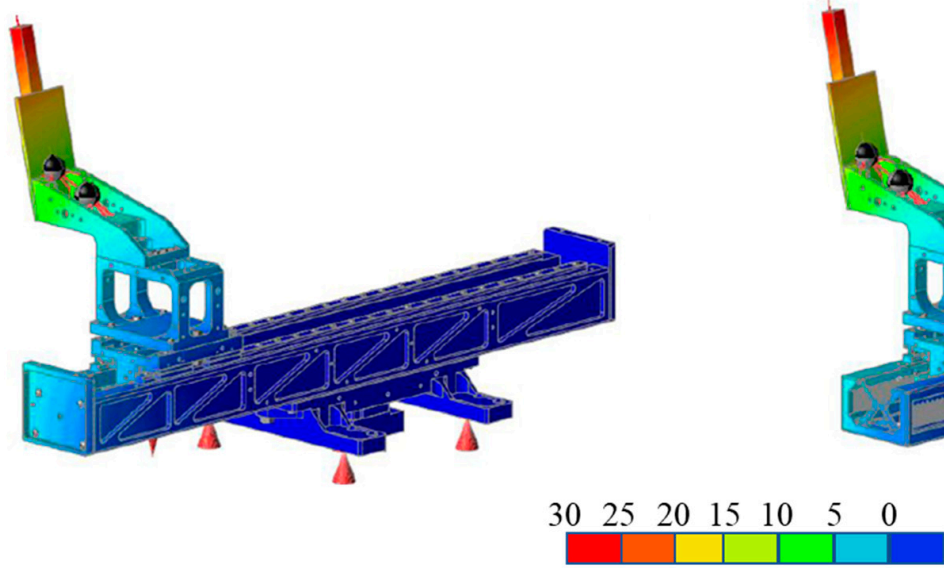

Max displacement $\left[10^{-3} \mathrm{~mm}\right]$

Figure 7. Comparison of the maximum displacements between the original and the new design. The maximum displacement is registered as the extremity of the probe. The slight difference in the displacements values between the two designs demonstrates that the stiffness of the system has been preserved while the material efficiency has been improved.
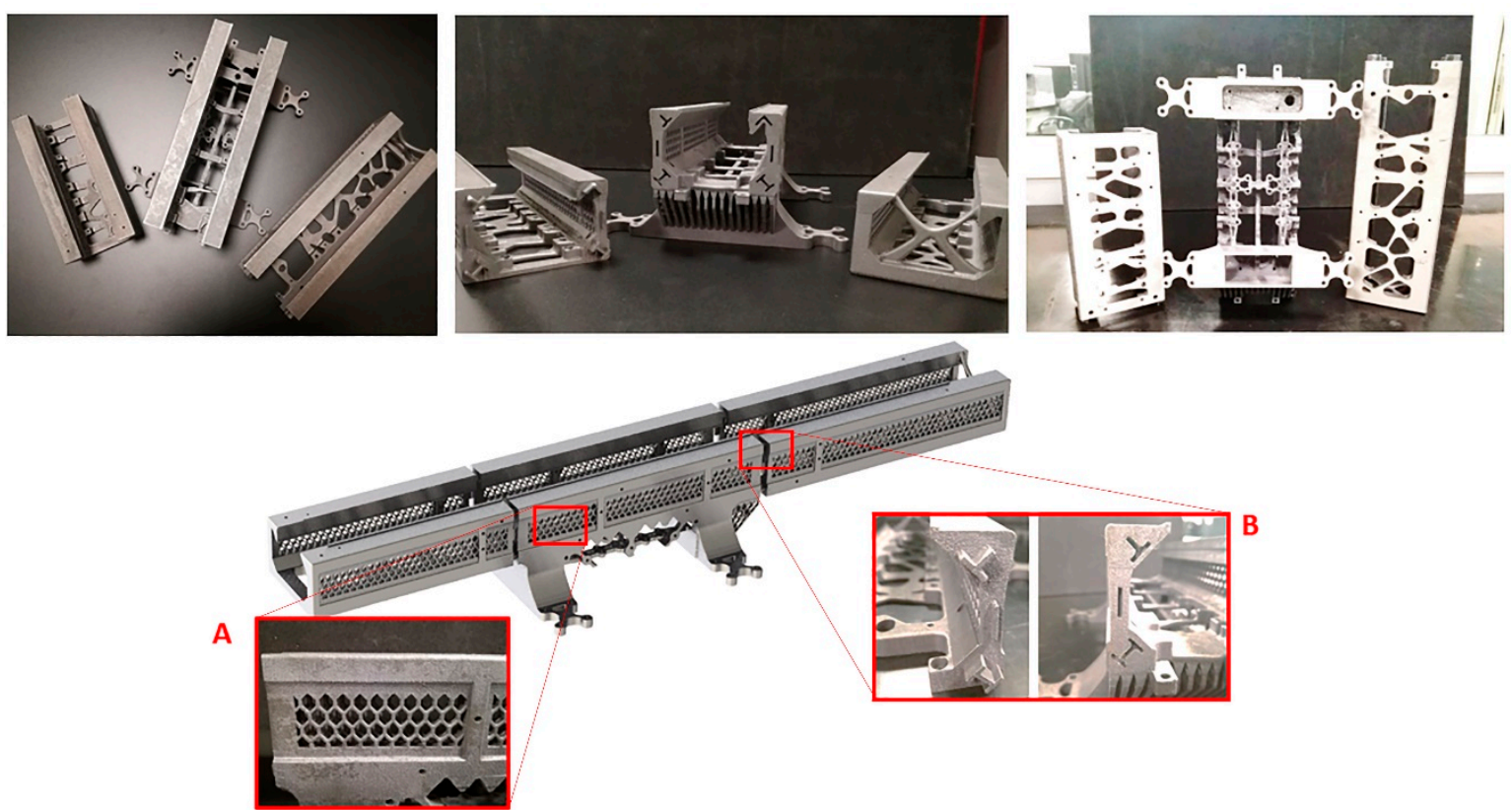

Figure 8. Technical prototype with details of the walls of the X-rail (A) and the shaft-hub interference fit (B).

\subsection{Bracket Design}

As already mentioned, the redesigning process had the aim of designing a bracket that would satisfy the original requirement, in terms of displacement, while maintaining its original weight. In order to maintain the original rail assembly operational flow, the coupling areas were constrained with other systems to avoid modifications as a result of the redesign. Some other surfaces were also included as constrained areas so that the same fastening tools used for the original geometry could be used during the finishing operations. 
Differently from the previous case, an increase of the stiffness is required here. Practically, this means a search of a new material distribution which considers a larger design domain of the original component. The design domain needs to be large enough to include the anticipated optimal material distribution, but also had to be as small as possible to avoid unfeasible structures and increases in the computational costs due to an abundance of unnecessary elements [36]. The potential design domain has been considered as the design space that does not compromise the fastening operations with the other systems. The design domain was therefore increased and optimized iteratively according to the following procedure:

1. Defining the initial design by increasing the updated design space without exceeding the maximum envelope:

- Identifying the areas with high deformation energy from the computer-aided engineering (CAE) analysis of the original design;

- Adding material to the areas that showed high deformation energy, after controlling that the total volume did not increase excessively. It noticed that, for small components, the total volume should not have exceeded twice the updated volume in order to avoid an excessive increase in the computational time. This rule was therefore followed in the subsequent steps.

2. Meshing the domain with a tetrahedral mesh which could be generated automatically, in order to decrease the computational time. In this step, the density of the mesh could be low.

3. Running a TO with free constraints and using the solid isotropic material with penalization (SIMP) method [37], which is implemented in the most frequently used commercial software programs, by constraining the weight to be equal to that of the original design (or a volume reduction of $50 \%$ ) and maximizing the stiffness.

4. Updating the optimized geometry (i.e., creating a geometry in which the areas with low deformation energy had been removed).

5. Verifying that the maximum stress did not exceed the material limit.

6. Establishing the maximum displacement of each axis; if the values did not exceed the prescribed condition, then the geometry obtained from step 4 could be considered optimal; otherwise, it was necessary to go to the next step.

7. Modifying the geometry obtained from step 4 by adding material to the areas with high deformation energy, while controlling that the total volume did not exceed twice the original volume. This model represents the new design space.

8. Go back to step 2 .

The as-defined design space results in being the smallest that would allow a solution to be found for the global displacement. In short, the proposed design space optimization procedure solves a displacement control problem by means of a series of structural TO problems in which the minimum compliance and volume constraint are considered. The maximum displacement is considered as the ideal design optimization criterion for the design space. Therefore, the design space is redefined several times, and the optimized geometry is obtained after iterations. These iterations work as a design space optimization as they allow the domain to be expanded, where necessary, regardless of the shape of the initial design domain. In other words, the displacement control problem is solved by means of iterative lightening procedures, in which the optimized goal is to find the structures with the maximum stiffness. That obtained design space design space was used in a free constraint TO using an improved mesh quality to provide a more precise solution [7] and allow a better representation of the structure.

The design optimization of both initial design domain and final geometry have been obtained by the TO method. The TO and validation of the optimized geometry were implemented and solved using Abaqus Standard and a TOSCA algorithm. Thanks to the design freedom, which is guaranteed by the design for the L-PBF process, TO was run with free constraints [38] and using the SIMP method [37]. 
A tetrahedral mesh was used for the design space optimization and for the final TO in order to decrease the computational time. Hexahedral elements were used for the analysis and validation of the geometry because the accuracy of the results was considered of utmost importance.

\subsubsection{Redesigning and Prototyping}

A preliminary static analysis of the original design of the bracket was performed to validate the FE model for the stiffness optimization. The analysis involved the implementation of an FE model of the original bracket, in which the mechanical stress and displacement behaviors were included. The probe and the vision system weights and the probing force during the measurement are the main causes of the bending of the bracket. The bending of the bracket was thus simulated for two different load cases. Load case 1 represents the situation in which the bracket is subjected to its own weight and to that of the other systems (vision and lighting systems and probe), while load case 2 represents the phase in which the probe tests a MEMS relay, and a probing force is therefore added. The maximum equivalent stress on the component was around $15 \mathrm{MPa}$ which was still below the limit of the material so as not to decrease the stiffness of the component. However, the maximum equivalent displacement was around $35 \mu \mathrm{m}$, in agreement with the specifications provided by the manufacturer. According to the procedure mentioned above, the design space was subjected to several iterations. An expansion of the original design is possible if the geometry modifications do not lead to a change in the finishing and assembly operations. The starting point was the original design for which the stresses and the displacements were known (Figure 9).

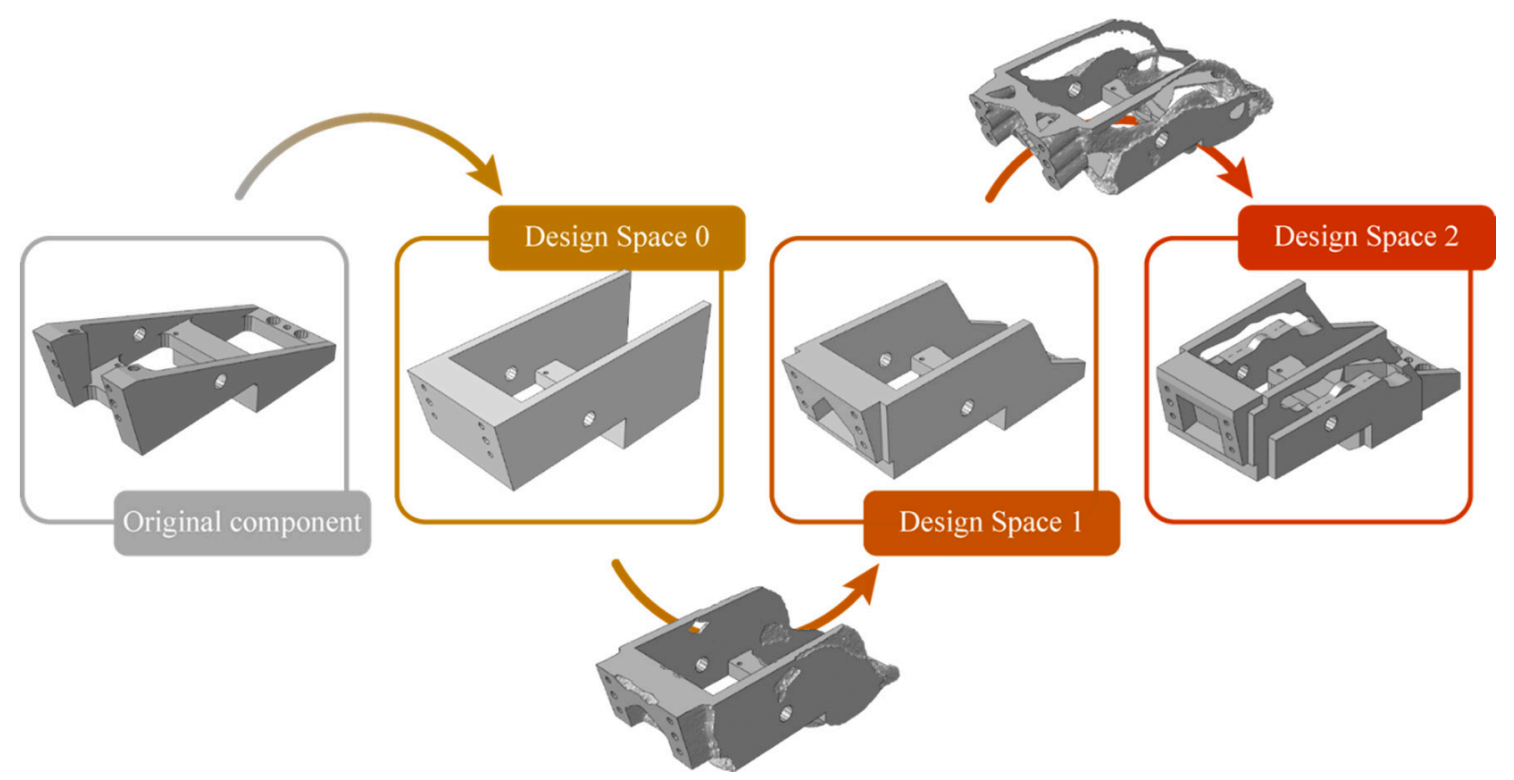

Figure 9. Iterations of the design space optimization. At each iteration, the material has been removed from the area at low energy deformation and has been added in the ones at high energy deformation. The iterations ended when the maximum displacement of the bracket under the load was less than the prescribed requirement $(20 \mu \mathrm{m})$.

Design space 0 was obtained by adding material to the areas with high deformation energy (Figure 9) while controlling that the total volume did not exceed twice the original volume. TO was then run by constraining the weight to be equal to the original design and maximizing the stiffness. The stresses and displacements were then analyzed. Design spaces 1 and 2 (Figure 9) were obtained from the previous design space in order to consider the optimized geometry by adding material to the areas with high deformation energy while controlling that the total volume did not exceed twice the original volume. Finally, when TO was run using design space 2, the displacement values did not exceed the prescribed condition, that is, $20 \mu \mathrm{m}$ and the space design was therefore considered 
optimal. Each design space was using Abaqus CAE and re-meshed considering the same element size. Design space 2 was then used to perform a more detailed optimization. The element was decreased in size to improve the approximation of the geometry.

The optimized geometry was redesigned, according to Section 2. Figure 10 shows a comparison of the original and the redesigned geometry displacements, which are reduced to the prescribed constraint in each direction. The maximum displacement was along axis 2 and was equal to $18 \mu \mathrm{m}$. Furthermore, the final design weighed $184 \mathrm{~g}$, which is about $10 \%$ less than the original bracket. This reduction in weight, in AM material, cannot be ascribed to the slightly lower density (Table 1) because the difference between the material density values is about $5 \%$.

\section{Load case 1}

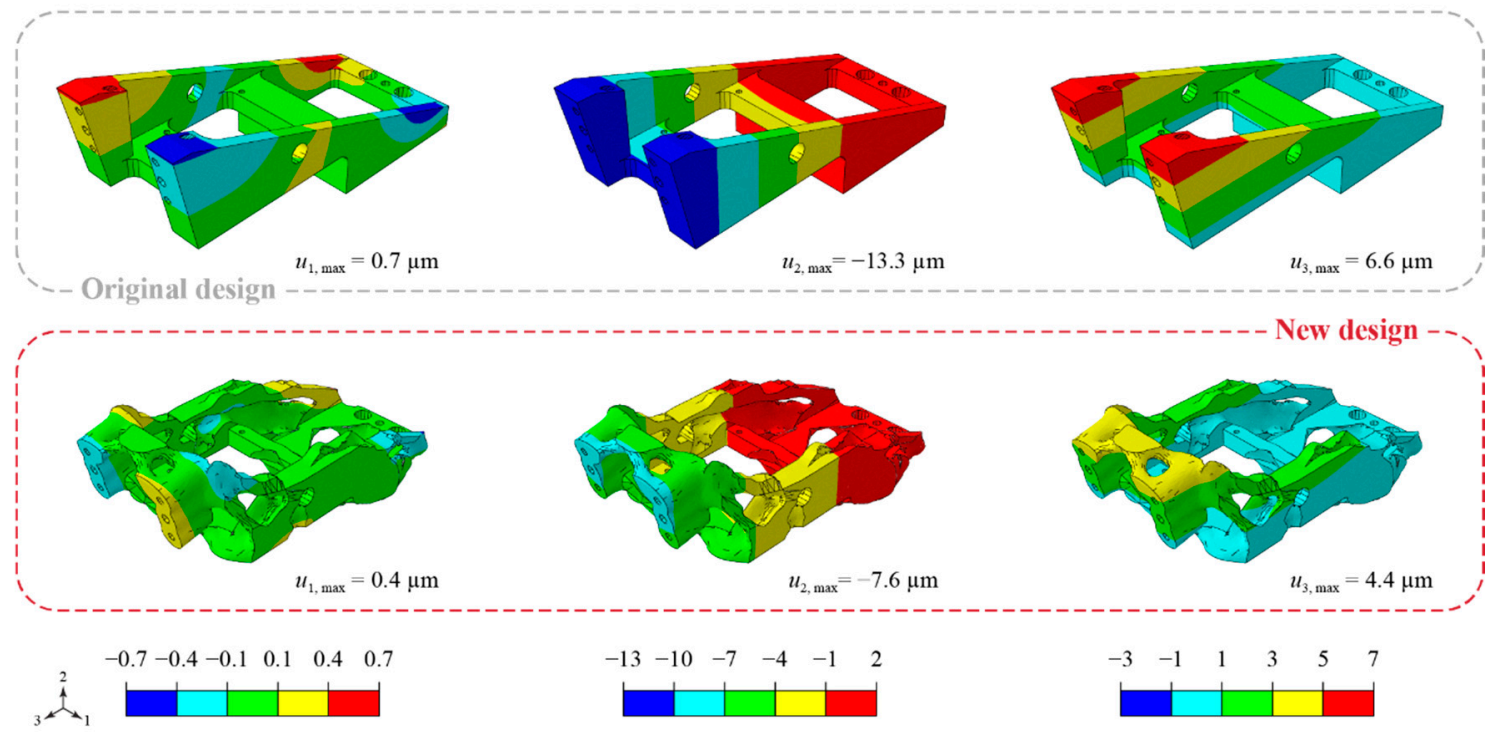

(a) Displacement $u_{1}(\mu \mathrm{m})$

(b) Displacement $u_{2}(\mu \mathrm{m})$

(c) Displacement $u_{3}(\mu \mathrm{m})$

Load case 2

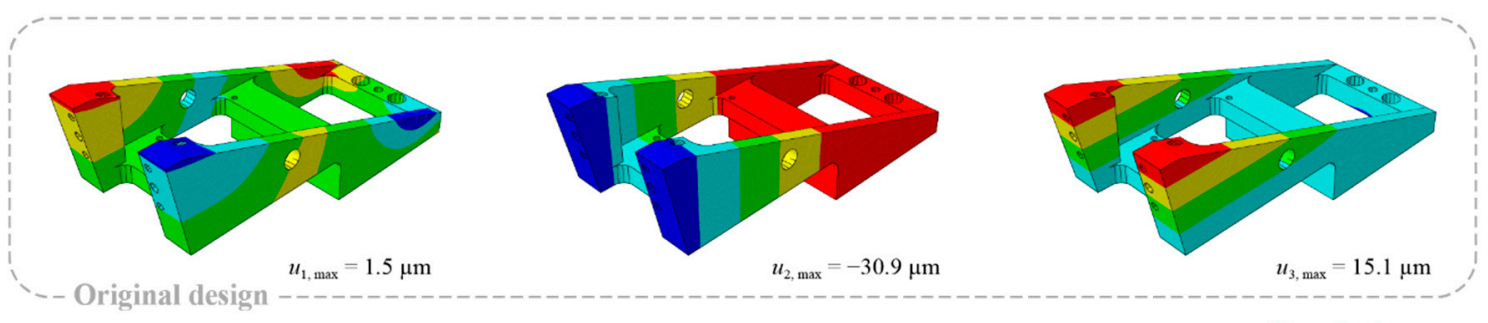

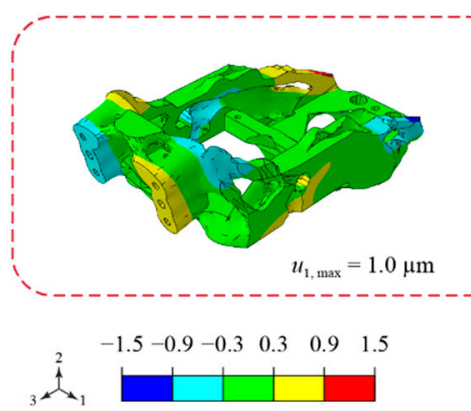

(a) Displacement $u_{1}(\mu \mathrm{m})$

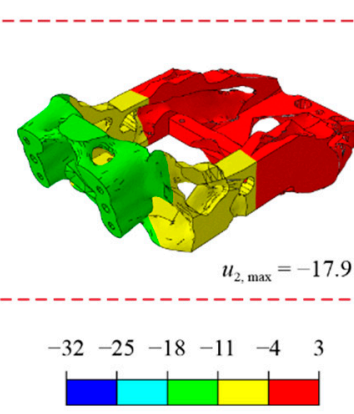

(b) Displacement $u_{2}(\mu \mathrm{m})$

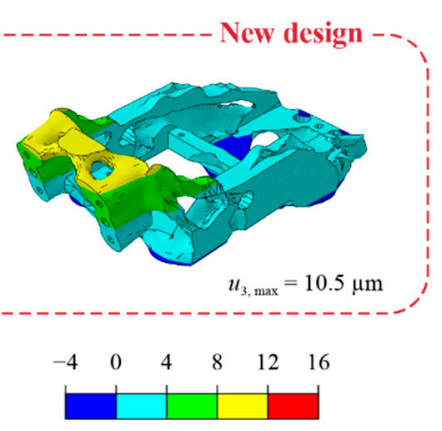

(c) Displacement $u_{3}(\mu \mathrm{m})$

Figure 10. Comparison of the original and new designs for load case 1 (the bracket is subjected to its own weight and to that of vision and lighting systems and a probe) and load case 2 (the probe tests a MEMS). The lower displacements in the case of the new design demonstrated an overall increasing of the stiffness of the bracket. 
The feasibility of the bracket in terms of part and process (choice of supports and orientation) designs has been verified by producing a single part. With this scope, the production has been performed by an EOSINT M270 Dual Mode machine that has a small production volume $\left(250 \times 250 \times 215 \mathrm{~mm}^{3}\right)$ which is suitable for the preliminary prototyping tests. An Ytterbium fiber laser system is used to melt powders with a continuous power of up to $200 \mathrm{~W}$, a spot of $100 \mu \mathrm{m}$, and scanning rate up to $7000 \mathrm{~mm} / \mathrm{s}$ in an argon atmosphere. The used process parameters are shown in Table 2. The produced component was heat-treated in a furnace $\left(2 \mathrm{~h}\right.$ at $\left.300^{\circ} \mathrm{C}\right)$ to prevent inaccuracies due to stresses induced thermally during removal of the parts. Figure 11 shows the as-built technical prototype in AlSi10Mg manufactured by the EOSINT M270 machine.

Table 2. Process parameter values employed for the bracket production.

\begin{tabular}{cccc}
\hline Process Parameters & Skin & Core & Contour \\
\hline Scan speed $[\mathrm{mm} / \mathrm{s}]$ & 900 & 800 & 900 \\
Laser power $[\mathrm{W}]$ & 120 & 195 & 80 \\
Hatching distance $[\mathrm{mm}]$ & 0.10 & 0.17 & - \\
Layer thickness $[\mu \mathrm{m}]$ & 30 & 30 & - \\
Laser spot size $[\mathrm{mm}]$ & 0.10 & 0.10 & 0.10 \\
\hline
\end{tabular}

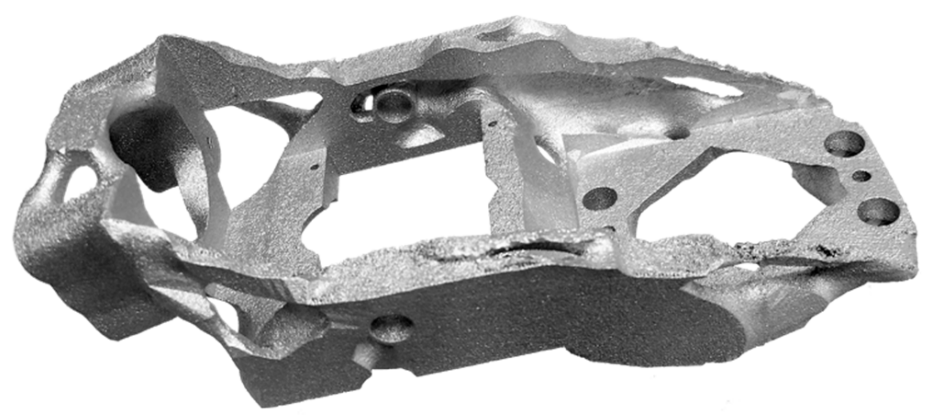

Figure 11. The technical prototype produced by EOSINT M270.

\subsubsection{Cost of the Bracket}

A production series of the bracket with the new design has been considered to compare the feasibility of the product and the actual cost with those of the original design. A production quantity of 400 parts per year was considered [35].

The time to produce the original design, using a milling machine, is about $1.40 \mathrm{~h}$, and the total cost is around $€ 116$ [35].

A SLM500 machine, made by SLM Solution, was considered for the simulation because, among the industrialized L-PBF systems, its building volume fits in a single job a higher number of brackets. The build volume is $500 \times 280 \times 365 \mathrm{~mm}^{3}$, where $500 \times 280 \mathrm{~mm}^{2}$ are the dimensions of the build platform (WxH). The price of the machine is around $€ 1,200,000$. The powder necessary to fill the tank (Mat filldisp$_{\text {) }}$ is about $50 \mathrm{~kg}$ in which a maximum height of the job and a dose factor equal to $27.3 \mathrm{~mm}$ and 4, respectively, have been considered. The manufacturing costs were simulated by considering the build platform to have been filled according to the procedure reported in Section 2. Nine parts can be produced for each job. An aliquot of $0.240 \mathrm{~kg}$ of material is necessary to build the part and supports $\left(\mathrm{W}_{\mathrm{m}}\right)$. An additional $5 \%$ is considered as powder lost during the cleaning of the part. After the production, the loose powder is removed from the parts and the as-built parts (attached to the building platform) are heat-treated to release the residual stresses. The supports are then removed manually. The pinholes and the holes for the bolts that join the probe to the bracket are the only surfaces that must be finished. It was assumed that all the manufacturing operations were performed in the same workshop.

The above-mentioned data are summarized in Table 3 . The coefficient $k_{1}$ is calculated by the ratio between the $\mathrm{V}_{\mathrm{O}+\mathrm{A}+\mathrm{S}}$ and the total job volume $\mathrm{V}_{\mathrm{job}}, \mathrm{k}_{2}$, and $\mathrm{k}_{3}$ are calculated according to Equations (4) 
and (5), while $\mathrm{k}_{4}$ is equal to zero because no cooling time is required after the production. The times included in Table 3 that are necessary to complete any manual operation or task was measured in real production. With this scope, a single part was produced using an SLM500 (Figure 12).

Table 3. General information about the cost of the model.

\begin{tabular}{ccc}
\hline $\begin{array}{c}\text { Material quantity for the build tank }[\mathrm{kg}] \\
\text { The dimension of the build platform }\left[\mathrm{mm}^{2}\right]\end{array}$ & $\begin{array}{c}\text { Mat }_{\text {filldisp }} \\
\text { Volume (part+supports) }\left[\mathrm{mm}^{3}\right]\end{array}$ & $500 \times 280$ \\
Material quantity (part+ supports) $[\mathrm{kg}]$ & & 90,000 \\
\% of waste & & 0.240 \\
Total material quantity [kg] & $\mathrm{W}_{\mathrm{m}}$ & 0.240012 \\
Number of parts per job & & 9 \\
$\mathrm{k}_{1}$ & & 0.11 \\
$\mathrm{k}_{2}$ & & 0.005 \\
$\mathrm{k}_{3}$ & & 0.11 \\
$\mathrm{k}_{4}$ & & - \\
Operation time & $\mathrm{t}_{\text {heating plat }}$ & 0.33 \\
Heating platform [h] & $\mathrm{t}_{\text {aux }}$ & 0.33 \\
Levelling platform [h] & $\mathrm{t}_{\text {fillAr }}$ & 1.67 \\
The time necessary to fill the chamber with Argon $[\mathrm{h}]$ & $\mathrm{t}_{\text {exp }}$ & 13 \\
The time necessary to complete the job [h] & $\mathrm{t}_{\text {hooling }}$ & - \\
Cooling time $[\mathrm{h}]$ & $\mathrm{t}_{\text {build }}$ & 1.7 \\
Total time per part [h] &
\end{tabular}
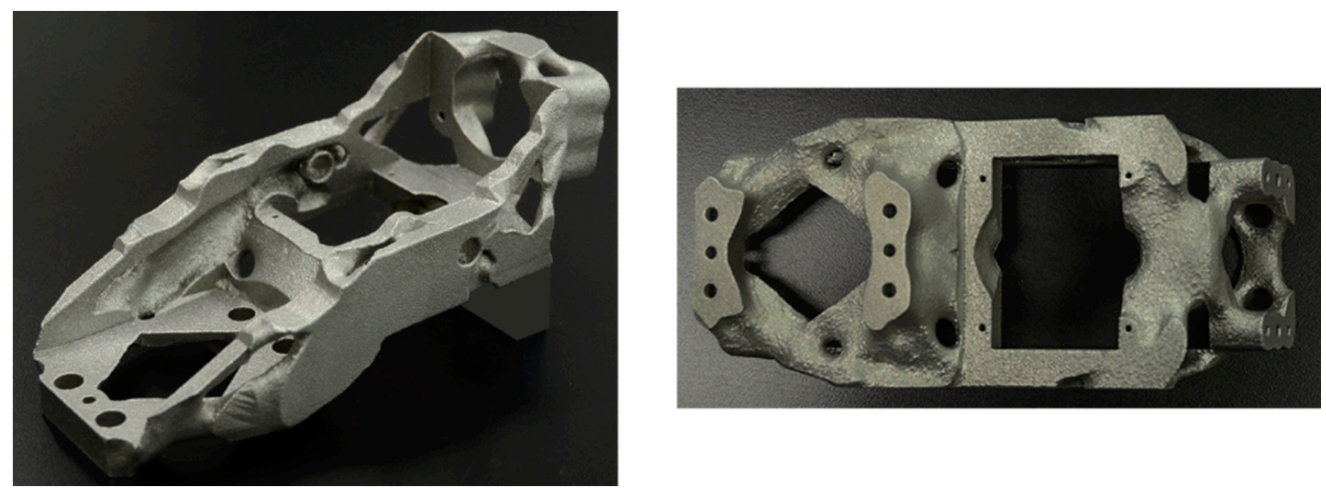

Figure 12. Part manufactured by SLM500. The idle times (Table 3) have been measured during the production.

Table 4 shows the calculation of each costs. The cost for a single part is obtained by dividing the cost for the number of brackets that are fabricated in a single job. The machining times were numerically calculated performing a 3-axis milling using computer-aided manufacturing (CAM) software, Visi 19. The same clamps used for the original designed were used. The costs of designing the part and the job were neglected because a large production was considered. 
Table 4. Calculation of the total manufacturing costs according to the model presented in Section 4.1.

* The volume of Argon necessary to fill the chamber, $V_{A r}$, is the product of $t_{\text {fillAr }}$ and $\mathrm{Ar}_{\mathrm{p}}$.

\begin{tabular}{|c|c|c|}
\hline \multicolumn{3}{|l|}{ Machinery Depreciation and Indirect Costs } \\
\hline Cost of the machine [€] & $\mathrm{C}_{\text {machine }}$ & $1,200,000$ \\
\hline Years & & 5 \\
\hline I & & 0.05 \\
\hline Depreciation cost $[€ / \mathrm{h}]$ & S & 76.58 \\
\hline Indirect costs $[€ / \mathrm{h}]$ & & 11.5 \\
\hline Indirect costs per part [€/part] & & 149.74 \\
\hline \multicolumn{3}{|l|}{ Setup Costs } \\
\hline Labor cost $[€ / \mathrm{h}]$ & Coper & 23 \\
\hline The time necessary to fill the dispenser [h] & $t_{\text {fill }}$ & 0.7 \\
\hline Cost of filling the dispenser [ $[€ /$ part $]$ & & 0.010 \\
\hline Time of the operator to start the process [h] & $t_{\text {operAr }}$ & 0.08 \\
\hline Cost of the Argon $\left[€ / \mathrm{m}^{3}\right]$ & $\mathrm{C}_{\mathrm{Ar}}$ & 3.7 \\
\hline Argon consumption for purging [1/min] & $\mathrm{Ar}_{\mathrm{p}}$ & 70 \\
\hline Total Argon volume to fill the chamber ${ }^{*}\left[\mathrm{~m}^{3}\right]$ & $\mathrm{V}_{\mathrm{Ar}}$ & 7.03 \\
\hline $\mathrm{C}_{\mathrm{env}}[€ /$ part $]$ & & 3.09 \\
\hline Machining cost $[€ / h]$ & $\mathrm{C}_{\text {machining }}$ & 35 \\
\hline Labor cost $[€ / \mathrm{h}]$ & $\mathrm{C}_{\text {oper }}$ & 23 \\
\hline Mill diameter $[\mathrm{mm}]$ & $\mathrm{D}$ & 100 \\
\hline Cost of resurfacing the building platform [€/part] & $\mathrm{C}_{\text {build plat }}$ & 2.05 \\
\hline Setup cost per part $[€ /$ part $]$ & $\mathrm{C}_{\text {setup }}$ & 5.15 \\
\hline \multicolumn{3}{|l|}{ Material Cost } \\
\hline Powder cost $[€ / \mathrm{kg}]$ & $\mathrm{C}_{\text {powder }}$ & 65 \\
\hline Material cost per part [€/part] & $\mathrm{C}_{\text {mat }}$ & 19.06 \\
\hline \multicolumn{3}{|l|}{ Production Costs } \\
\hline Cost of the Argon $\left[€ / \mathrm{m}^{3}\right]$ & $\mathrm{C}_{\mathrm{Ar}}$ & 3.7 \\
\hline Argon consumption during the building $[1 / \mathrm{min}]$ & $\mathrm{Ar}_{\mathrm{b}}$ & 5 \\
\hline Total Argon volume for building $\left[\mathrm{m}^{3}\right]$ & $\mathrm{V}_{\mathrm{Ar}}$ & 0.433 \\
\hline$A M$ cost $[€ / h]$ & $\mathrm{C}_{\mathrm{AM}}$ & 10 \\
\hline Production cost per part [€/part] & $\mathrm{C}_{\text {production }}$ & 18.60 \\
\hline \multicolumn{3}{|l|}{ Post-processing costs } \\
\hline Labor cost $[€ / h]$ & $\mathrm{C}_{\text {oper }}$ & 23 \\
\hline $\mathrm{EDM}$ cost $[€ / \mathrm{h}]$ & $\mathrm{C}_{\mathrm{EDM}}$ & 30 \\
\hline The time necessary to remove the supports manually [h] & $t_{\text {rem }}$ & 1 \\
\hline Heat treatment cost $[€ / \mathrm{h}]$ & & 35 \\
\hline Heat treatment time $[\mathrm{h}]$ & & 8 \\
\hline Polishing cost $[€ / \mathrm{h}]$ & & 5 \\
\hline The time necessary to remove the powder [h/part] & & 0.16 \\
\hline Post processing cost per part [€/part] & $\mathrm{C}_{\text {post proc }}$ & 43.69 \\
\hline Manufacturing cost $[€ /$ part $]$ & & 247.59 \\
\hline Finishing operation cost $[€ /$ part $]$ & & 52.7 \\
\hline Total cost $[€ /$ part $]$ & & 300.37 \\
\hline
\end{tabular}

The manufacturing cost for the new design ( $€ 300.37)$ results in being more than twice those of the original bracket. Figure 13 compares the distribution of each cost item over the total manufacturing costs for the new design and the original one. It may be observed that the largest contributions to the AM processes are those of the depreciation of machinery and the indirect costs. This is because these costs are computed on the basis of the build time. In fact, the production time of L-PBF machines is longer than that of the traditional manufacturing process. The depreciation of machinery and the production costs for a 3-axis CNC (computer numerical control) process are distributed equally over the total costs. In fact, the total hourly production cost for a traditional machine considers the maintenance of the machine, the tools, the equipment, the lubrication, the cooling system and energy consumption, 
the operator, movement of the pallet, and so on. As a result, the total hourly production cost for a traditional process is higher than that of an AM process. A large part of the cost of the new design is due to the post-processing and finishing operations. As the currently used L-PBF processes can only produce near-net shaped parts, the total production cost of obtaining a functional part, by means of L-PBF, should be considered as the sum of the production cost, the post-processing and the finishing cost. Accordingly, it is evident that the distribution of the costs of traditional and AM processes is similar. Although it is generally believed that the price of powders influences the final cost of the part to a great extent, the here presented analysis instead shows that the main influence on L-PBF is the production rate, in other words, the time necessary to produce a part and to finish it. The cost of the material to produce the original design, by means of milling, is comparable with the cost of the material necessary to produce the newly designed part produced by L-PBF. However, the cost of the material for 3-axis CNC has a significant effect on the total cost because a large quantity of material is wasted during machining. In fact, a $2.2 \mathrm{~kg}$ ingot of material is needed to produce a bracket that weighs $203 \mathrm{~g}$.

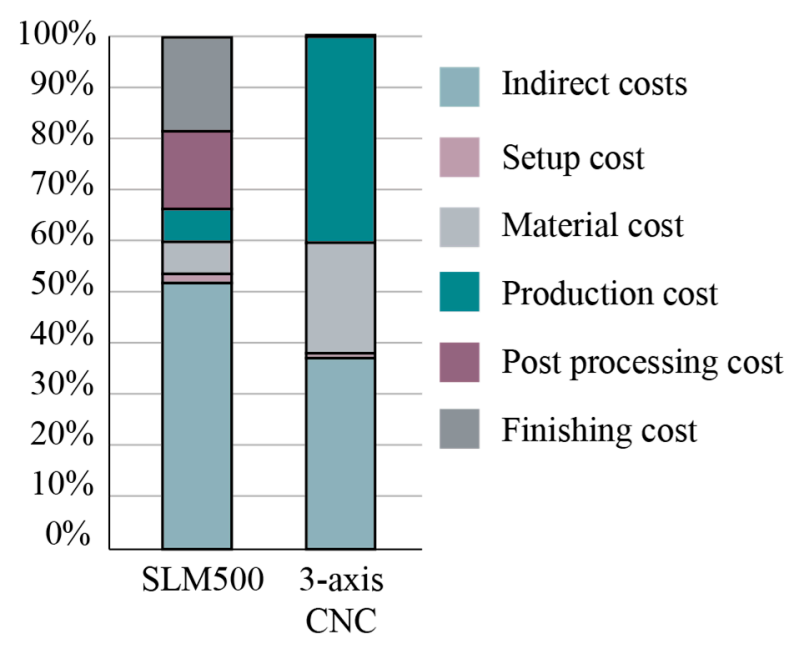

Figure 13. Distribution of the manufacturing costs.

Besides the increased cost, the benefit that was achieved by adopting the new geometry, and thus the AM process adopted to produce the part, should be considered from an overall point of view. The new design for L-PBF has shown the possibility of achieving the required stiffness, which in turn improves the actual machine accuracy and dynamics because the load on the electric motor is decreased. Therefore, the higher cost, with respect to the 3-axis CNC, could be justified by the increase in the performance of the component and in turn of the whole machine. The same conclusion cannot be reached when the new design and the 3-axis CNC process are adopted because the complexity of the geometry would lead to an exponential increase in manufacturing costs.

\section{Conclusions}

The here presented work is aimed at exploiting the production advantages of L-PBF systems for high-precision applications, in which the design problems pertain to the assembly operations, weight reductions and increasing the stiffness. In this context, the rails and bracket that support a high-precision flying probe for a testing machine have been redesigned. The redesign is based on a general methodology that considers all the steps of an L-PBF process. The optimization of the design, the support and the part orientation have been driven by material efficiency. The components that have been redesigned to be produced by L-PBF have demonstrated great advantages, in terms of mechanical performance. The weight of the rails has been reduced by $32 \%$, while the number of components has been reduced from 16 to 3 . The optimized bracket results in being more than $50 \%$ stiffer than the original one and about $10 \%$ lighter. In both cases, CAE simulations have shown that great improvements can be achieved as a result of new material distribution. The results have thus 
provided further validation of the fact that an integrated approach between design and AM processes is an extremely powerful tool to generate geometries with high performances and characteristics, even in the case of precision machines, coordinate measuring machines, and industrial robots, in which the mechanical stiffness of the parts, without any extra weight, is one of the most important design criteria. The cost analysis has also confirmed the suitability of adopting a new manufacturing process to produce components for this industrial sector. The higher cost of the new design of the bracket, with respect to the original one, appears negligible compared to the improvements that can be achieved in terms of component performance and machine accuracy. Additionally, the increased cost appears to be a small part if compared with the market price of these kinds of machines (around $€ 700,000$ ). Compared with the traditional process, DfAM leads to significant savings in material. As a result, the use of AM leads to positive environmental impacts, in terms of material utilization, the supply chain, and life-cycle performances [39].

Overall, AM processes shorten the distance between concept and reality. However, the empirical findings of this study suggest important issues that should be considered in future research:

- The support structures and finishing operations still represent a challenge for the full exploitation of the AM process and for the creation of optimized geometries;

- The available commercial tools are still not able to fully support the designer to find optimal design solutions for AM and to handle geometric complexities;

- At present, the application of an iterative approach to designing seems to be the only way to:

- reach an optimal solution that takes advantage (for specific purposes) of the level of complexity of the design made available as a result of the adoption of AM processes;

- achieve the production of truly optimized parts.

Supplementary Materials: The following are available online at http://www.mdpi.com/2073-4352/10/3/161/s1, Figure S1: Comparison of the Von Mises stress between the original and the new design. As can be observed, the stress on both parts is extremely low. The maximum values around ( $24 \mathrm{MPa})$ is registered in the contact between the bolts the rails (Figure S2). The low stresses and great safety coefficient respect to the yield stress of the material (503 MPa for the Al7075 of the original design and $350 \mathrm{MPs}$ for the AlSi10Mg of the new design) are due to the high stiffness requirements which were applied the design stage (which means low deformation and displacements during the working conditions of the system), Figure S2: Localisation of the only areas in which the maximum stress has been registered, Figure S3: Design details of the shaft-hub interference. The features have been designed to guarantee an adequate stiffness of the connection. This is ensured not only by the feature 'dimensions but also by the roughness of tilted surfaces that is slightly higher of the horizontal and vertical ones and helps to improve the contact between the surface.

Author Contributions: Conceptualization, M.G. and L.I.; methodology, M.G. and F.C.; software, M.G. and M.V.; validation, M.G., F.C. and M.V.; formal analysis, M.G.; investigation, M.G.; resources, L.I.; data curation, M.G.; writing—original draft preparation, M.G.; writing—review and editing, M.G. and F.C.; visualization, M.G. and F.C.; supervision, L.I. All authors have read and agreed to the published version of the manuscript.

Funding: This research received no external funding.

Conflicts of Interest: The authors declare no conflict of interest.

\section{References}

1. Gibson, I.; Rosen, D.W.; Stucker, B. Additive Manufacturing Technologies; Springer: New York, NY, USA, 2015; Volume 17.

2. Salmi, A.; Calignano, F.; Galati, M.; Atzeni, E. An integrated design methodology for components produced by laser powder bed fusion (L-PBF) process. Virtual Phys. Prototyp. 2018, 13, 191-202. [CrossRef]

3. Saadlaoui, Y.; Milan, J.L.; Rossi, J.M.; Chabrand, P. Topology optimization and additive manufacturing: Comparison of conception methods using industrial codes. J. Manuf. Syst. 2017, 43, 178-186. [CrossRef]

4. Biamino, S.; Penna, A.; Ackelid, U.; Sabbadini, S.; Tassa, O.; Fino, P.; Pavese, M.; Gennaro, P.; Badini, C. Electron beam melting of Ti-48Al-2Cr-2Nb alloy: Microstructure and mechanical properties investigation. Intermetallics 2011, 19, 776-781. [CrossRef] 
5. Galati, M.; Iuliano, L. A literature review of powder-based electron beam melting focusing on numerical simulations. Addit. Manuf. 2018, 19, 1-20. [CrossRef]

6. Brackett, D.; Ashcroft, I.; Hague, R. Topology optimization for additive manufacturing. In Proceedings of the 22nd Annual International Solid Freeform Fabrication Symposium-An Additive Manufacturing Conference, SFF 2011; University of Texas at Austin (freeform), Austin, TX, USA, 17 August 2011; pp. 348-362.

7. Aremu, A.; Ashcroft, I.; Hague, R.; Wildman, R.; Tuck, C. Suitability of SIMP and BESO topology optimization algorithms for additive manufacture. In Proceedings of the 21st Annual International Solid Freeform Fabrication Symposium (SFF)-An Additive Manufacturing Conference, Austin, TX, USA, 9-11 August 2010; pp. 679-692.

8. Rozvany, G.I.N. A critical review of established methods of structural topology optimization. Struct. Multidiscip. Optim. 2009, 37, 217-237. [CrossRef]

9. Li, B.; Ge, L.; Hong, J. An intelligent computational approach for design optimization of stiffened engineering structures. Int. J. Precis. Eng. Manuf. 2017, 18, 1005-1012. [CrossRef]

10. Doubrovski, Z.; Verlinden, J.C.; Geraedts, J.M.P. Optimal design for additive manufacturing: Opportunities and challenges. In Proceedings of the ASME 2011 International Design Engineering Technical Conferences and Computers and Information in Engineering Conference, Washington, DC, USA, 28-31 August 2011; American Society of Mechanical Engineers: New York, NY, USA, 2011; pp. 635-646.

11. Seepersad, C.C. Challenges and opportunities in design for additive manufacturing. 3D Print. Addit. Manuf. 2014, 1, 10-13. [CrossRef]

12. Großmann, A.; Weis, P.; Clemen, C.; Mittelstedt, C. Optimization and re-design of a metallic riveting tool for additive manufacturing-A case study. Addit. Manuf. 2020, 31, 100892. [CrossRef]

13. Häußler, P.; Emmrich, D.; Müller, O.; Ilzhöfer, B.; Nowicki, L.; Albers, A. Automated topology optimization of flexible components in hybrid finite element multibody systems using ADAMS/Flex and MSC. Construct. In Proceedings of the ADAMS European User's Conference, Berchtesgaden, Germany, 14-15 November 2001; pp. 14-15.

14. Tomlin, M.; Meyer, J. Topology optimization of an additive layer manufactured (ALM) aerospace part. In Proceedings of the 7th Altair CAE Technology Conference, Warwick, UK, 10 May 2011; pp. 1-9.

15. Vayre, B.; Vignat, F.; Villeneuve, F. Designing for additive manufacturing. Procedia CIrP 2012, 3, $632-637$. [CrossRef]

16. Hilpert, E.; Hartung, J.; Risse, S.; Eberhardt, R.; Tünnermann, A. Precision manufacturing of a lightweight mirror body made by selective laser melting. Precis. Eng. 2018, 53, 310-317. [CrossRef]

17. Jang, J.; Choi, W.C. Error Compensation Using Variable Stiffness in Orbital Grinding. Int. J. Precis. Eng. Manuf. 2018, 19, 317-323. [CrossRef]

18. Suh, N.P. Axiomatic Design and Fabrication of Composite Structures: Applications in Robots, Machine Tools, and Automobiles; Oxford University Press: Oxford, UK, 2005; ISBN 0198039751.

19. Ito, S.; Iijima, D.; Hayashi, A.; Aoyama, H.; Yamanaka, M. Micro turning system: A super small cnc precision lathe for microfactories. In Proceedings of the 3rd International Workshop on Microfactories, Minneapolis, MN, USA, 16-18 September 2002; pp. 37-40.

20. Neugebauer, R.; Wabner, M.; Rentzsch, H.; Ihlenfeldt, S. Structure principles of energy efficient machine tools. CIRP J. Manuf. Sci. Technol. 2011, 4, 136-147. [CrossRef]

21. Oiwa, T. Coordinate measuring machine using parallel mechanism. In Proceedings of the Proc. 16th IMEKO World Congress, Vienna, Austria, 25-28 September 2000; Volume 8, pp. 211-214.

22. Calignano, F.; Cattano, G.; Manfredi, D. Manufacturing of thin wall structures in AlSi10Mg alloy by laser powder bed fusion through process parameters. J. Mater. Process. Technol. 2018, 255, 773-783. [CrossRef]

23. Calignano, F.; Galati, M.; Iuliano, L. A metal powder bed fusion process in industry: Qualification considerations. Machines 2019, 7, 72. [CrossRef]

24. Vayre, B.; Vignat, F.; Villeneuve, F. Metallic additive manufacturing: State-of-the-art review and prospects. Mech. Ind. 2012, 13, 89-96. [CrossRef]

25. Yang, S.; Zhao, Y.F. Additive manufacturing-enabled design theory and methodology: A critical review. Int. J. Adv. Manuf. Technol. 2015, 80, 327-342. [CrossRef]

26. Adam, G.A.O.; Zimmer, D. On design for additive manufacturing: Evaluating geometrical limitations. Rapid Prototyp. J. 2015, 21, 662-670. [CrossRef] 
27. Mumtaz, K.A.; Hopkinson, N. Selective laser melting of thin wall parts using pulse shaping. J. Mater. Process. Technol. 2010, 210, 279-287. [CrossRef]

28. Kumke, M.; Watschke, H.; Vietor, T. A new methodological framework for design for additive manufacturing. Virtual Phys. Prototyp. 2016, 11, 3-19. [CrossRef]

29. Leary, M.; Merli, L.; Torti, F.; Mazur, M.; Brandt, M. Optimal topology for additive manufacture: A method for enabling additive manufacture of support-free optimal structures. Mater. Des. 2014, 63, 678-690. [CrossRef]

30. Calignano, F. Design optimization of supports for overhanging structures in aluminum and titanium alloys by selective laser melting. Mater. Des. 2014, 64, 203-213. [CrossRef]

31. Rickenbacher, L.; Spierings, A.; Wegener, K. An integrated cost-model for selective laser melting (SLM). Rapid Prototyp. J. 2013, 19, 208-214. [CrossRef]

32. Baumers, M.; Dickens, P.; Tuck, C.; Hague, R. The cost of additive manufacturing: Machine productivity, economies of scale and technology-push. Technol. Forecast. Soc. Chang. 2016, 102, 193-201. [CrossRef]

33. Moylan, S.; Slotwinski, J.; Cooke, A.; Jurrens, K.; Donmez, M.A. Lessons Learned in Establishing the NIST Metal Additive Manufacturing Laboratory. NIST Rep. 2013. [CrossRef]

34. He, G.; Guo, L.; Li, S.; Zhang, D. Simulation and analysis for accuracy predication and adjustment for machine tool assembly process. Adv. Mech. Eng. 2017, 9, 1687814017734475. [CrossRef]

35. SPEA Automatic Test Equipment Personal comunication. Via Torino, 16, 10088 Volpiano TO, Italy. 2019.

36. Kim, I.Y.; Kwak, B.M. Design space optimization using a numerical design continuation method. Int. J. Numer. Methods Eng. 2002, 53, 1979-2002. [CrossRef]

37. Lee, S.M.; Han, S.Y. Topology optimization scheme for dynamic stiffness problems using harmony search method. Int. J. Precis. Eng. Manuf. 2016, 17, 1187-1194. [CrossRef]

38. Gibson, I.; Rosen, D.W.; Stucker, B. Desing for additive manufacturing. In Additive Manufacturing Technologies: Rapid Prototyping to Drect Digital Manufacturing; Springer: Boston, MA, USA, 2010; pp. 299-332, ISBN 9781441911193.

39. Hao, L.; Raymond, D.; Strano, G.; Dadbakhsh, S. Enhancing the sustainability of additive manufacturing. In Proceedings of the 5th International Conference on Responsive Manufacturing-Green Manufacturing (ICRM 2010), Ningbo, China, 11-13 January 2010.

(C) 2020 by the authors. Licensee MDPI, Basel, Switzerland. This article is an open access article distributed under the terms and conditions of the Creative Commons Attribution (CC BY) license (http://creativecommons.org/licenses/by/4.0/). 